\title{
The meronomic model of cognitive change, and its application to neolithic Çatalhöyük
}

\author{
Chris Thornton \\ University of Sussex \\ Brighton \\ UK \\ c.thornton@sussex.ac.uk
}

August 29, 2019

\begin{abstract}
The attempt to relate changes in human cognition to changes in human behaviour can be fruitful for cognitive science and archaeology alike. The process has the potential to enrich both our understanding of cognition, and interpretations of the archaeological evidence. A practical difficulty is the lack of clarity as to what cognitive change refers to. Characterisations vary considerably, even in regard to locus. Use of broad-brush terminology (e.g., 'higher levels of consciousness') can add to the uncertainty. The present chapter argues that an effective way to understand cognitive change is in terms of conceptual structure, and the meronomic processes that apply. Building on the ontological distinction between meronomy and taxonomy, this approach allows cognitive change (by conceptual innovation) to be modeled precisely, while opening the way for quantification of conceptual creativity. This chapter shows how the model is derived, and explores some of the ways it might be connected with data from Çatalhöyük.
\end{abstract}

\section{Introduction}

There is a natural desire to explain the development of cognitive phenomena that seem particularly characteristic of the human mind. Creativity is a case in point, consciousness another. A recent archaeological project has attempted to understand evidence from the neolithic site of Çatalhöyük in relation to emergence of both consciousness and creativity at the dawn of settled life. This project faces the need to settle on a precise understanding of what is meant by the terms in question. But theorists differ as to what this understanding should be. And there are deeper disputes relating to cognition in general. What the term 'cognitive' signifies continues to be debated, with some arguing that it has 
no precise meaning that would differentiate it from terms such as 'adaptive' and 'intelligent'.

A major aim of the project is to understand the degree to which cognitive change underlies behaviors that seem to have occurred at this site. This necessitates adopting a model of cognitive change. What is argued here is that a meronomic model is well suited to this purpose. Meronomic analysis allows cognitive change (by conceptual innovation) to be modeled in a precise way. It also allows conceptual creativity to be quantitatively assessed. This is subject to some reservations, however. Given the hope of the approach being of use in an archaeological setting, it is worth examining the pros and cons in more detail.

Functionalities of the human mind, cognitive or otherwise, remain relatively mysterious at this time. Proposals are forthcoming (e.g., Gärdenfors, MIT, 2004; Clark, 2016) but consensus remains elusive. The lack of agreement obstructs any project which seeks to make reference to mental phenomena in an instrumental way (e.g., to explain archaeological evidence). Ventures in this direction can be made. But as they are forced to adopt a specific view of cognition, their fate is bound up with the view in question. Mithen's (1996) original approach in cognitive archaeology, for example, adopted Fodor's (1983) proposal for a modular mental architecture, and was bound to it for that reason.

With cognitive science unable to settle on a received view of cognition, the prospects for a robust cognitive archaeology may seem limited. But a meronomic approach gets around this to some degree. The framework makes no assumptions about the mind, other than that it trades in the identification of categories. That this capacity exists is universally agreed; the use of mental concepts is accepted by all theorists (Machery, 2009). (The cognitive science view of a concept as a mental representation of a category is assumed throughout.) In practice, the existence of mental concepts can hardly be denied, since without them there can be no language, and without language, there can be no denials.

How is this of use? The starting point in the meronomic approach is recognition that concepts are inherently accommodative. Due to the way one concept may be able to accommodate others in combination, they can be assembled into hierarchical structures. We can conceptualize a combination of food and water as sustenance, for example. What this reveals is that the concept of sustenance has the capacity to accommodate the concepts of food and water taken in combination. These three concepts can be assembled in a hierarchical structure, with the concept of sustenance in the accommodative role. Other hierarchical arrangements of these three concepts are semantically illegitimate. We cannot conceptualize water to be a combination of food and sustenance, for example.

This capacity for accommodation endows concepts with mathematical properties. Specifically, it renders them inherently generative. Any set of concepts gives rise to a (possibly empty) set of accommodative structures. These can be derived in a purely analytic way, by identifying all legitimate accommodations. This becomes of interest from the cognitive point of view, as it provides a way of analyzing the compositional conceptualizations that a particular endowment of 
concepts enables. The degree to which a construction is novel can be measured in a formal way. This leads on to a way of modeling conceptual change and creativity that is essentially mathematical in nature.

This does not solve the problem that we do not know with any certainty what cognition is, or how it works. It does not provide archaeologists with what is required for truly robust projects in cognitive archaeology. Due to its minimal supposition, and its reliance on formal analysis, it does provide leverage, however. To undertake meronomic analysis, we only have to specify the endowment of concepts that is assumed to exist initially. Any results obtained are of cognitive significance if the mind (or more specifically the conceptual system) can utilize conceptual accommodation. This is not to assume very much, given our self-evident capacity to compose accommodative constructions by means of language (as illustrated above).

A meronomic brand of cognitive archaeology retains some degree of immunity from changing fashions in cognitive science, then. A particular proposal must assume some endowment of concepts, and it has the potential to be criticised or invalidated thereby. The award of cognitive significance to the results obtained also requires the assumption that conceptual accommodation is within the repertoire of the mind. Otherwise, the approach is an exercise in purely formal analysis, and no less secure as such that any mathematical calculation.

It is useful to be clear about how this relates to the general issue of conceptualization, however. Interpretation of materials and activities is obviously something archaeologists have great interest in. To interpret evidence of human activity in the past, it is necessary to make assumptions about the meanings, interpretations, categories etc. that underpinned those activities. There has to be some understanding of how worldly phenomena were 'chunked' by the people in question. Vigorous debate on this issue is the natural result. An important theme is the danger of over-extending the modern mindset. The temptation to apply a modern conceptual apparatus to settings in which it may have played little or no role is strengthened by the necessity to use modern language in stating any proposal. As modern language is saturated with the modern mindset, expressing ideas that deviate from it is less than straightforward.

This gives rise to cautionary notes, such as Keane's assertion that 'language should not be the privileged theoretical model for a semiotics of material things' (Keane, 2003, p. 422). The need to resist specific emphases is also highlighted. Pauketat notes (with approval) the increasing tendency in archaeology to reject traditional 'dualisms that separate thought and action' (Pauketat, 2013, p. 35), while Keane acknowledges (with disapproval) the lingering tendency 'to divide our attention between things and ideas' (Keane, 2005, p. 182).

Specific proposals for new forms of conceptualization are made. Keane and Pauketat both favour the idea of a 'bundle' as a fundamental unit of conceptualization (Keane, 2005; Pauketat, 2013). ${ }^{1}$ It is argued that, in addition to other benefits, viewing things in this way can overcome the modern tendency to

\footnotetext{
${ }^{1}$ Pauketat advocates 'viewing the world as dynamic relationships mediated by bundles' (Pauketat, 2013, p. 56).
} 
separate continuity and change. In Pauketat's opinion, 'Using the metaphorical language of a bundle ... we might begin to see continuity and change as one and the same phenomenon' (Pauketat, 2013, p. 55). Such proposals inevitably face the difficulty that meaningful exchange 'requires a shared language and a medium of communication' (Keane, 2005, p. 200). To the extent that this necessitates sharing a conceptual apparatus, ventures towards significantly different interpretations of the world are inherently problematic.

As it involves assuming an initial endowment of concepts, a meronomic approach is, to some extent, subject to these concerns. At the same time, it can claim some degree of independence. Which concepts are assumed to be endowed is not the critical issue, as they may form only a small subset of the concepts that can be generatively derived. The commitment to an initial conceptual endowment is not a commitment to a whole conceptual apparatus - only to its seeds. The conceptual apparatus is a potentially large derivation from the initial endowment. The natural objective in a meronomic approach is to assume a minimal number of concepts of maximal generative capacity, then. The conceptual apparatus then derived has the potential to depart from the modern mindset to an arbitrary extent. Any meronomic approach should aim to restrict the assumed endowment in this way.

The remainder of the article set out the approach in more detail, and examines how it can be used to model cognitive change and conceptual creativity. The eventual aim is to roadtest the method as a way of assessing evidence from Çatalhöyük. The section immediately following examines the mechanics of meronomic composition, taking particular account of its less obvious aspects. The role potentially played by singular accommodations and abstract concepts is highlighted. Section 3 explores the ways in which the meronomic model lends itself to quantitative assessment of conceptual creativity. Finally, Section 4 considers application of the model to evidence of human behavior at neolithic Çatalhöyük.

\section{Meronomic conceptual change}

As noted, the ability of concepts to compose meronomically derives from their capacity for accommodation. Suppose the combination of an X and a Y can be conceptualized as a $\mathrm{Z}$ (where $\mathrm{X}, \mathrm{Y}$ and $\mathrm{Z}$ are concepts). This establishes that concept $\mathrm{Z}$ is able to accommodate the concept combination $\mathrm{X}+\mathrm{Y}$. The three concepts are potentially organized in a hierarchical structure, with $\mathrm{Z}$ as parent (or holonym), and $\mathrm{X}$ and $\mathrm{Y}$ as children (or meronyms). To illustrate: the combination of a lawn and flowerbed can be conceptualized as a garden. This establishes that GARDEN can accommodate the combination LAWN + FLOWERBED. ${ }^{2}$ There is a valid meronomic arrangement of concepts in which GARDEN is the parent (holonym), and LAWN and FLOWERBED are the children (meronyms). Using the terminology of Artificial Intelligence, the structure consists of two has-a

\footnotetext{
${ }^{2}$ Concept names are written in upper case throughout.
} 
links: one from GARDEN to LAWN, and another from GARDEN to FLOWERBED (Brachman, 1983).

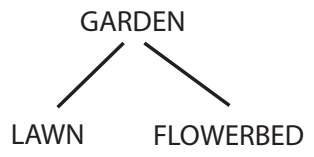

Figure 1: Meronomic organization of GARDEN, LAWN and FLOWERBED reflecting the capacity to conceptualize the combination of a lawn and flowerbed as a garden.

The structure is drawn out in Figure 1 in the conventional way, with root pointing upwards. There are two ways to describe what is expressed. The hierarchy can be seen as the construction of a concept. Putting the cited concepts together in this hierarchical way has the effect of constructing a specialization of the garden concept; namely, the concept of a garden comprising a lawn and flowerbed. Viewed this way, the hierarchy is a compositional construction. Alternatively, we can view it in a decompositional way. The structure can be seen to express a way of decomposing the concept of garden. On this view, what is specified is the potential for a garden to have a lawn and flowerbed as parts.

It will be seen that the two views are two sides of the same coin. In one case, we focus on how a complex idea can be put together; in the other, on how it can be broken down. Historically, the decompositional interpretation has been particularly prominent, however. Dubbing meronomies 'part-whole hierarchies' or even 'partonomies' (Tversky, 1989, p. 983), theorists have seen them primarily as a way of representing knowledge about how concepts of wholes decompose into concepts of parts (e.g. Winston and Herrmann, 1987). In some cases, theorists have taken the step of viewing the meronomy as a type of conceptual analysis (e.g. Gerstl and Pribbenow, 1995). The structure has been seen as the ontological counterpart of the taxonomy - a way of using hierarchical structure to show necessary conceptual relationships. According to this view, taxonomic organization of concepts expresses relations of subsumption, while meronomic organization expresses relations of 'parthood' (Tversky, 2005). ${ }^{3}$

The analytic view of the meronomy has proved problematic, however, due to the inherent subjectivity of meronomic composition. The fact that the combination of a lawn and flowerbed can be conceptualized as a garden falls short of being an analytic truth. This is just one of many - perhaps infinitely manyways to conceptualize the constitution of a garden. As Tversky points out, concepts 'can be decomposed in many different ways' (Tversky, 2005, p. 9). Furthermore, parts can 'be optional; in the sense, they might or might not appear in the whole to which they relate' (Fiorini and Gärdenfors, 2014, p. 138).

\footnotetext{
${ }^{3}$ Tversky, for example, recognizes 'two general forms of organization of knowledge, taxonomic, that is, subdivision into kinds, and partonomic, that is, subdivision into parts' (Tversky, 1989, p. 983).
} 
This and other problems affecting the analytic view of the meronomy have been widely debated in the field of Ontology (Cruse, 1979; Johansson, 2006). ${ }^{4}$

\subsection{Variations in constructive form}

The construction discussed above - a lawn and flowerbed conceptualized as a garden - is typical in its use of concrete concepts and two-way branching. A meronomic unit can have any number of branches, however. The structure can be of any depth, and the concepts featured can be arbitrarily abstract. The structures of Figure 2 illustrate some of the possibilities. Consider the top left hierarchy. A journey can be conceptualized as combining a flight and a drive. Hence, there is a valid meronomic unit with JOURNEY as parent, and FLIGHT and DRIVE as children. This is the structure shown. Its meaning is the concept we started with: a journey involving a flight and drive. ${ }^{5}$ The top right hierarchy illustrates use of three-way branching. A ceremony, betrothal and reception taken together can be conceptualized as a wedding. Hence there is a valid meronomic structure as shown. What is constructed is the concept of a wedding with this makeup.

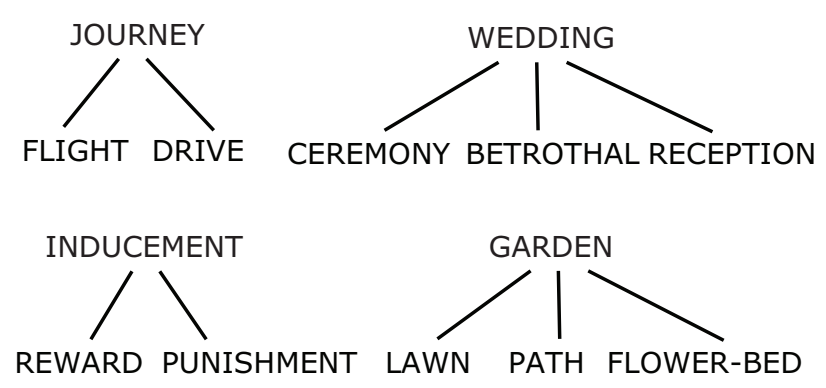

Figure 2: Meronomies illustrating variation in accommodative inclusivity and conceptual abstraction.

The bottom left structure illustrates the potential for accommodation to be noticeably inclusive. The combination of a bribe and fine can be conceptualized as an inducement. Hence, INDUCEMENT can be the parent of a meronomic unit which has BRIBE and FINE as children. The meaning obtained is the idea we started with: a bribe and fine conceptualized as an inducement. As well as using abstract concepts, this structure exploits accommodation that is rather general relative to what is accommodated. An inducement can have many other constitutions, of many different kinds. The effect of the construction is thus to specialize the accommodating concept's meaning quite considerably. The

\footnotetext{
${ }^{4}$ Habel et al. (1995) draw attention to the difficulty of stabilizing the semantics of the parthood relation.

${ }^{5}$ This article takes 'meaning', 'idea' and 'concept' to be synonymous, and uses them interchangeably.
} 
existence of many alternatives is implied. (This harks back to Tversky's (2005) point, that concepts can be decomposed in many different ways. The more general the accommodating concept is, the more ways it can be (de)composed.)

The potential for use of singular accommodations is also of note. A lawn by itself can be conceptualized as a garden. Hence there is a valid hierarchical construction which has GARDEN as parent, and LAWN as child. What is obtained is the idea of a lawn conceptualized as a garden (i.e., the idea of a garden consisting solely of a lawn). Other examples of singular accommodation can be visualized. A disagreement can be conceptualized as a battle: BATTLE can accommodate DISAGREEMENT. Fishing can be conceptualized as a pastime: PASTIME can accommodate FISHING. With these singular constructions, it becomes natural to use the phrase 'classified as' instead of 'conceptualized as'. The three constructions above can be considered to stem from the fact that a lawn can be classified as a garden, that a disagreement can be classified as a battle, and that fishing can be classified as a pastime. This style of description will be used wherever possible.

With the potential for singular accommodations taken into account, it is possible to identify one way in which meronomy is related to taxonomy. Imagine a singular accommodation in which the accommodated concept is subsumed by the accommodating concept (i.e., where the extension of the latter is within that of the former). Given a fine can be classified as a penalty, we might have a structure with PENALTY as parent, and FINE as child, for example. As a fine is a special case of a penalty, this is, in fact, ordinary class subsumption. The construction is an $i s-a$ link in effect. Taxonomy can be seen as a limiting case of meronomy in this situation. For all practical purposes, a meronomy passes muster as a taxonomy if all accommodations are singular, and all are class-subsumptive. Another special case occurs if the accommodating concept in a meronomic unit is COMBINATION itself. A new concept is then composed, but in a redundant way. What is accommodated is a combination by definition. Accommodation using COMBINATION, or any equivalent, is redundant. ${ }^{6}$

Making full use of the meronomic repertoire, and exploiting the potential for multi-level constructions, conceptual meanings of considerable complexity can be built up. Singular accommodations provide a way of expressing basic attributes and properties. A chair can be classified as red (RED can accommodate CHAIR). Children can be classified as young (YOUNG can accommodate CHILDREN). Snow can be classified as deep (DEEP can accommodate SNOW). Constructions like these can also be used to assemble concepts of role. Children can be classified as the agent of an action. Snow can be classified as the target

\footnotetext{
${ }^{6}$ There is a philosophical dimension to this. If the accommodating concept in a meronomic construction is not COMBINATION (or some equivalent), the idea constructed is then more than simply the 'sum of the parts'. The construction conforms to requirements that philosophers generally consider to apply to concepts of wholes. Aristotle, for example, states that 'The whole is something over and above its parts, and not just the sum of them all' (Metaphysics, Book H, 1045: 8-10: Ross, 1924). In similar vein, John Stuart Mill writes 'it appears to me the Complex Idea, formed by the blending together of several simpler ones, should ... be said to result from, or be generated by, the simple ideas, not to consist of them' (Mill, 1843/1965, p. 29).
} 
of an action, and so on.

Concepts constructed by singular accommodations can be incorporated into more complex structures to obtain meanings not unlike those we encounter in language. Consider the idea of a rock blocking a stream. A blockage can be conceptualized as having an agent in the form of a rock (a rock classified as agent), and an object in the form of a stream (a stream classified as object). Hence there is a valid meronomic construction which has BLOCKAGE as parent, and ROCK classified as AGENT as one child, and STREAM classified as OBJECT as the other. This hierarchical arrangement of concepts constructs the concept of a rock blocking a stream (see Figure 3 ).

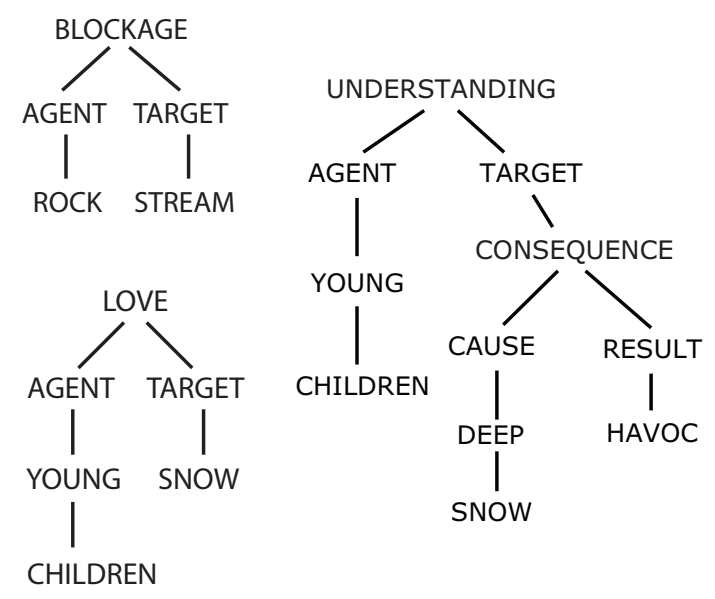

Figure 3: Meronomic construction of ideas involving agents and targets.

This example illustrates that placing concepts into a meronomic hierarchy can produce ideas involving agents and objects, taking roles in specific types of action. The semantic possibilities can be further illustrated by making minor changes to the structure. Say we change ROCK to CHILDREN. The structure now yields the idea of children blocking a stream. Say we also change BLOCKAGE to LOVE, and STREAM to FRUIT. This idea obtained is now that children love fruit. Changing LOVE to FEAR, FRUIT to SNAKES, and ChILDREN to PEOPLE produces the idea that people fear snakes, and so on.

These examples also highlight use of recursion. The output of any meronomic construction is a new concept; new concepts are the ingredients for new constructions. Meronomic construction is a fully recursive procedure. In principle, the depth of a meronomic hierarchy is unbounded for this reason. An example showcasing three levels of construction appears in the bottom left of Figure 3. This is the top left structure with BLOCKAGE changed to LOVE, and ROCK changed to CHILDREN. The additional structural element has the effect of classifying CHILDREN as YOUNG. As a result of these changes, what is obtained is the idea that young children in particular love snow. 
A more complex case is illustrated on the right. This hierarchy embeds one three-level construction within another. A consequence can be conceptualized as having a cause in the form of deep snow, and a result in the form of havoc. This reveals the potential for a two-child arrangement of concepts in which CONSEQUENCE is the parent. Assuming HAVOC is made the child of RESUlt, and CAUSE is made the parent of a subconstruction which has DEEP as the parent of SNOW, what is obtained is the idea of havoc being a consequence of deep snow.

The meaning of the enclosing construction can then be established. An understanding can be conceptualized as having an agent in the form of young children, and an object in the form of the consequence in question. There is a valid hierarchical arrangement which makes UNDERSTANDING the parent of the relevant structures. One of the structures builds the idea of an agent in the form of young children. The other, the idea of the consequence just described. The overall meaning is then that young children understand that deep snow causes havoc. Again, variations can be envisaged. Changing UNDERSTANDING to LOVE yields the idea that young children love the idea that deep snow causes havoc. Changing SNOW to RAIN, and DEEP to HEAVY produces that idea that young children understand that heavy rain causes havoc.

With abstract concepts, singular accommodation and recursion all brought into play, conceptual accommodation is found to be have considerable semantic fertility, then. The ability that concepts have to fit together meronomically allows complex ideas to be assembled. Semantic precision is always retained, however. The meaning of any complex derives directly from the meaning of its components: it is the meaning of the accommodating element conceptualized as accommodating the meanings of the accommodated elements (taken together). A meronomic structure always defines its meaning in this compositional way, directly expressing the compositionality principle (Szabó, 2012). The capacity of concepts to compose meronomically is found to be inherent to their capacity for accommodation.

How does this model of conceptual construction relate to the general issue of conceptualization, as viewed from the archaeological point of view? Understanding the meanings, signs, concepts, categories etc. salient to a particular time and place is a matter of great importance in archaeology. Reference has already been made to Pauketat's (2013) proposal to do this by means of the notion of a 'bundle', where this construct can assemble phenomena as, of or in time. Pauketat envisages entire networks of 'sacred objects, ceremonial buildings, human bodies, celestial bodies, and unseen spirits [being] seamlessly bundled, connected, embodied, and emplaced' (Pauketat, 2013, p. 44). This way of conceptualizing phenomena departs from the modern way of thinking, and may or may not be achaeologically useful accordingly. The meronomic model of conceptualization has no implications either way. Its only supposition is that cognition involves the grouping (chunking) of phenomena. Bundling being a way of grouping phenomena, there is no inconsistency. Proposals of this nature can sit along side the meronomic model of conceptual construction. 


\section{Quantifying creativity}

An advantage of meronomic analysis is its potential use for quantifying conceptual creativity. On the face of it, all meronomic constructions are alike in terms of novelty. Every construction accommodates a certain combination of concepts within another concept. The procedure never varies. Constructions may differ considerably, however, in the degree to which they create extensional novelty.

The extension (or, more formally, extensional meaning) of a concept is the set of entities to which it refers (Carnap, 1947). The extension of RED is the set of all red things. The extension of BRIBE is the set of all bribes, and so on. A meronomic construction produces a new concept by combining concepts hierarchically. What is the extensional meaning of a concept constructed in this way? As extensional meanings are sets, we know that accommodation of one extensional meaning within another entails the accommodation of one set within another. This is the operation that we call set intersection. But it is important to recognize that what is accommodated - and thus intersected - is the joint extension of the combination. The rule that applies is as follows:

- The extensional meaning of a meronomic construction is the joint extension of the accommodated combination intersected with the extension of the accommodating concept.

Consider the example of a bribe and fine jointly conceptualized as an inducement. The extensional meaning is the set of all inducements intersected with the set of all bribe + fine combinations. Contrast this with the case of a grate, hearth and chimney jointly conceptualized as a fireplace. In the latter case, the extensional meaning is the set of all fireplaces intersected with the set of all grate + hearth + chimney combinations. The two examples differ considerably in terms of extensional novelty. The combination of a grate, hearth and chimney is a fireplace almost by definition: virtually all fireplaces have this make-up. The intersection differs little from the two sets from which it is derived. The extensional meaning derived has little if any novelty.

In the case of a bribe and fine conceptualized as an inducement, the derived intersection is more novel. As inducements can take many other forms than bribe + fine combinations, and as a bribe + fine combination can be many things other than an inducement, the intersection deviates more significantly from its two sources. Accordingly, the outcome is a more novel extensional meaning. An effective way to understand novelty in the context of meronomic conceptualization, then, is in terms of extensional innovation. In what follows, constructions will be termed inventive if the associated extension differs significantly from the two sets from which it is derived, and derivative otherwise.

In an extreme case of inventive construction, the derived intersection may be empty, but potentially filled in by application of background knowledge. Consider, for example, a lake and river jointly conceptualized as a warrior. The intersection of the set of all warriors with the set of all lake + river combinations 
would seem to be empty. But it is not impossible to imagine a phenomenon that might be characterised in this way. (Imagine, for example: rainfall causes the lake to expand and the river to flood, resulting in the action of the river destroying dwellings.) Cases of this type will be termed radically inventive.

A second aspect of novelty involves productivity. As every meronomic construction creates a new concept, and as new concepts are the ingredients of new meronomic constructions, any construction has the potential to give rise to (i.e., enable) others. Constructions can have knock-on effects. If we take the position that concepts of greater novelty are likely to be more productive, this becomes a second way of quantifying conceptual creativity. The more a construction provides the means of making further constructions, the more it can be described as novel. The terms potent and inert will be used to characterize this. The former term will designate a construction that is especially productive; the latter, one that is not. Equipped with this basic, quantitative terminology, the meronomic model can be used to explore creative aspects of cognitive conceptual change, in relation to archaeological evidence.

\section{Application to archaeological evidence}

As an initial exploration of how the model can be applied to archaeological data, it is useful to focus on some evidence reported by Gebel (2002, 2013). Gebel records that, at the neolithic site of Ba'ja, small stone tools seem to have been inserted into walls as a method of symbolic reinforcement. In his words,

the hidden objects used in the walls and floors most likely served as a forceful "medicine" against evil influence; hammerstones and celts, but also grinders, all representing heavy-duty tools, could have been understood as practical instruments to strengthen a wall ... Strength was added to the structure, especially necessary with the terraced architecture of Ba'ja (Gebel, 2002, p. 131).

Gebel sees the introduction of heavy-duty tools to reinforce weak walls as application of a 'forceful medicine'. It is possible to look at this from a meronomic point of view. The starting point for this is to define the conceptual endowment people are assumed to possess in advance. Given Gebel's interpretation, it seems reasonable to suppose a repertoire of basic concepts would have been in currency. Assume that at least the following were included: WALL, TOOL, STONE, EARTH, HARD OBJECT, LIFE and SOURCE. A concept of the IMPLANTING (of an object) also seems to be implied, along with something like a concept of HARVESTING (of power).

With these concepts assumed to be possessed, it is possible to consider the conceptual innovations that might have precipitated the behavior of placing heavy-duty tools into walls. One scheme focuses on the materials from which a wall can be constructed. A wall is potentially conceptualized as a combination of stone and earth. Assuming a stone can be classified as a hard object, there is a potential analogy between stones and heavy-duty tools, traced through the 
hardness that they have in common. Given one meronomic construction featuring HARD OBJECT as parent of STONE, and another featuring HARD OBJECT as parent of TOOL, an association between the two children is formed, potentially enabling the former to substitute for the latter. On this account, the conceptual process is not complex. But the innovations involved do seem to entail some element of creativity. Both the enabling conceptualizations would appear to be towards the inventive end of the inventive/derivative spectrum.

An alternative scheme focuses on the potential role of IMPLANTING. Being users of agriculture, people of this time may have conceptualized implanting as life making (in the sense that planting a seed has this effect). This could set the stage for a cognitive sequence in which the placement of a tool into a wall is conceptualized as implanting, and hence as life making. On this interpretation, a heavy-duty tool might be understood to be placed into a wall as a way of giving the wall the strength of life specifically. In a variation on the theme, the wall might be conceptualized as an extension of the ground, rather than as a structure placed over it. This could potentially reinforce conceptualization of the act as a form of implanting.

The latter of these two schemes may be closer to what Gebel has in mind when he speaks of 'forceful medicine'. The meronomic structures involved seem not to be implausible, at least not from a modern perspective. The indications of conceptual creativity are perhaps slightly stronger in the latter of the two accounts. In both cases, the enabling constructions are towards the inventive end of the inventive/derivative spectrum. But, in the latter case, the conceptual connection established between implanting and agriculture has a potential potency extending beyond the immediate context of wall construction.

\subsection{Evidence from Çatalhöyük}

Archaeological evidence from the site of Çatalhöyük is particularly intriguing from the conceptual point of view. Of the activities the occupants of the site engaged in, much is known. How these activities were conceptualized is far less clear. There is considerable scope for framing hypotheses of a meronomic nature. The aim here will be to look for evidence of creativity in ordinary day-to-day activities, building in particular. This is not to deny there is considerable evidence of seemingly artistic creative activities, such as wall painting, figurine making, body adornment, bead making, and so on. It simply reflects the degree to which the creative implications of those activities have been examined elsewhere [citation of relevant chapter(s)]. The review of the archaeological evidence below draws primarily on Ian Hodder's introductory presentation to the 'Consciousness and Creativity at the Dawn of Settled Life' conference at the McDonald Institute for Archaeological Research, University of Cambridge, July 27-July 30 2017; information is also taken from (Hodder, 2006a, 2006b, 2012), and from the Çatalhöyük Research Project website. The assumed initial endowment of concepts remains as above.

The starting point in the interpretation of neolithic Çatalhöyük is generally Mellaart's (1967) conception of the site as a town. The site is known to consist of 
a large number of rectangular brick buildings, and these are generally interpreted as the dwellings of a settlement, spread over multiple levels. It has emerged, however, that the site lacks many of the features one would expect to find in a settlement, and the extent to which houses were used as places of burial has also become apparent. This raises a basic question of interpretation. Were the buildings of Çatalhöyük conceptualized as houses for the living, or houses for the dead? In meronomic terms, the question is whether the conceptualization of a building was more akin to a construct with DWELLING or TOMB as parent.

The two possibilities can be compared for the degree that they imply acts of conceptual creativity. The buildings of Çatalhöyük have ovens and hearths, and show unequivocal evidence of cooking and food-consumption. On the basis that cooking facilities play a vital part in any human dwelling, a conceptualization based on DWELLING is surely not unrealistic. Meronomically, it would seem to be towards the derivative end of the inventive/derivative dimension.

Not all the evidence points in this direction, however. Many facilities that would seem to play an important role in a structure conceptualized as a dwelling are found to be missing. It is now recognized that the buildings had no windows, for example. Apparently, this does not reflect a lack of window-making know-how, as lintels were used internally (for doors). Mellaart (1967) assumed the buildings must have had windows, and took the step of visualizing them pictorially. But hard evidence of their existence has not been obtained. As well as having no windows, the buildings lack external doors. In place of external doors, they have roof hatches, allowing descent by ladder. Internal arrangements are also seemingly at odds with the purpose of a dwelling. Where internal doors exist, they may be too low to walk through, necessitating the use of crawling. Most strikingly of all, buildings were used for burying the dead, with the siting of graves within buildings being highly organized and systematic. The extent to which this activity existed is also of note. Buildings have been found to contain more than 60 graves.

Some of the infrastructural evidence also seems antithetical with the settlement interpretation. The buildings are crammed together wall-to-wall, meaning that moving from the bottom to the top of the settlement would have involved clambering over a series of roofs, all at different elevations (Hodder, 2006b). Transporting heavy objects or building materials from one location to another would presumably have been nightmarishly difficult. There are no streets or communal spaces, and scant evidence of neighbourhoods. ${ }^{7}$ At its peak, it is thought the site would have involved the lives of as many as eight thousand people. Yet evidence of the non-house-based industrial and commercial activities such a substantial population would imply is lacking. Signs of communal gathering are detected, but only some way away from the site.

The archaeological data reveal that at some point in the life of a building, it would be dismantled/demolished and possibly burned as well. It would then be replaced with a construction immediately above, and essentially identical to

\footnotetext{
${ }^{7}$ At the consciousness and creativity conference, Colin Renfrew characterized his reaction to this aspect of the evidence as 'bemusement'.
} 
the one demolished. There are indications of this activity having a mortuary purpose. The layout of graves (including what are described as 'bone nests') at one level would be replicated in the building above, suggesting an attempt to connect the dead together by physical alignment.

From the meronomic point of view, there are various ways to approach this puzzling evidence. Conceptualization of the buildings as dwellings might represent a meronomic construction of extreme inventiveness; i.e., accommodation within DWELLING of a combination of phenomena that would fail most tests of dwelling-hood. On this view, the act can be seen as considerably creative, at least in terms of extensional innovation. At the same time, it is difficult to see how it could lead on to others, on which basis it would also appear to be of low potency. The indications for conceptual creativity are contradictory in this sense. Conceptualization of the buildings as dwellings suggests considerable creativity on the inventive/derivative dimension, but less so on the potent/inert dimension.

An alternative scheme is more along the lines of the IMPLANTATION interpretation of Gebel's heavy-tool example. The starting point, in this case, is the assumption of the buildings being, not houses for the living, but houses for the dead. The main construction is envisaged to have something like TOMB, rather than DWELLING as its parent. Again, there are suggestions that any such structure would be conceptually inventive. All the buildings at Çatalhöyük incorporate ovens and cooking areas, and there is evidence of these being used for normal daily consumption of food. To the extent that cooking and eating seem not to be constitutive of tomb-hood, a conceptualization based on TOMB would seem to be inventive necessarily.

On the other hand, even in the modern world, eating and burial-making can be combined, as in a wake. So accommodation of these activities within the concept of a tomb may not be entirely ruled out. Again, the concept of IMPLANTATION could play a connective role. If placement of the dead into carefully sculpted graves is assumed to be conceptualized as entombment, this might imply a conceptual connection with the idea of implantation into a life source (i.e., the ground). In light of the evidence of dwellings being systematically dismantled and burned, conceptualization of the buildings might then deviate significantly from the modern idea of a tomb. It might refer to an 'elaborate mortuary ceremonialism' more generally (Pauketat, 2013, p. 47), in which demolition and burning of a tomb is used to finally convey the dead back into what is conceptualized as the source of life.

This scheme assumes several interlocking constructions, some of which might be inventive. Conceptualization of a brick construction as a vehicle would certainly count as such if it were made in the face of extensional meanings with no intersection. Similarly, with the combination of burial-making and feast-making conceptualized as an implantation. Given the range of possible accommodations of IMPLANTATION, this particular construction would seem especially inventive. Also of interest is the conceptualization of physical alignment as a means of securing a physical connection. This also suggests inventive processes of conceptualization. 
There are, in addition, indications of constructive potency, however. If we assume the dismantling and burning of buildings was conceptualized as a way of consolidating the transmission of dead occupants into the ground, this might imply conceptual connections with other cases of deliberate breakage. Gebel records the finding of an intentionally broken 'flint dagger found in a collective burial' (Gebel, 2013, p. 200). If deliberate breakage of a weapon can be related to deliberate destruction of buildings at Çatalhöyük, this might imply the existence of a very potent originating conceptualization dealing with breakage and its capacity to connect life and death. It is not impossible to see in this signs of substantive conceptual creativity on the inert/potent dimension.

Generally, then, meronomic assessment of the evidence from Çatalhöyük can be developed in at least two ways. Which version is preferred depends on whether the buildings are interpreted as houses for the living, or houses for the dead. It depends, ultimately, on whether archaeologists come to interpret the site as a settlement of dwellings distributed over multiple levels, or as one or more mounds of composited tombs. In either case, it is possible to interpret the behaviors that seem to be implied as showing evidence of conceptual creativity on the inventive/derivative dimension. But the interpretation of the site in terms of tomb-mounds seems to open the way for richer interpretations of creativity on the inert/potent dimension.

The final conclusion of the present approach, then, has to be that the building activities evidenced at Çatalhöyük can certainly be interpreted as expressing conceptual creativity. But it seems such interpretations are developed more easily, and to a greater extent if the site is viewed as a compositing of tombs, than as a settlement. To the extent that cognitive change can be modeled as conceptual creativity, the case for detecting manifestations of cognitive change at the site is not lacking in foundation. Analysis to see if this result can be taken forward and made precise might pay dividends. The fabulously rich data emerging from the excavation of Çatalhöyük is surely a treasure trove for cognitive science, no less than for archaeology. It is hoped that future applications of meronomic analysis will be able to contribute to understanding what the people of this time and place really had in mind.

\section{References}

Brachman, R. J. (1983). What IS-A is and isn't: An Analysis of Taxonomic Links in Semantic Networks. IEEE Computer, 16, No. 10.

Carnap, R. (1947). Meaning and Necessity: a study in semantics and modal logic, Chicago, IL: University of Chicago Press.

Clark, A. (2016). Surfing Uncertainty: Prediction, Action, and the Embodied Mind, Oxford: Oxford University Press.

Cruse, D. A. (1979). On the Transitivity of the Part-Whole Relation. Journal of Linguistics, 15 (pp. 29-38). 
Fiorini, S. R. and Gärdenfors, P. (2014). Representing part-whole relations in conceptual spaces. Cognitive Processing, 15, No. 2 (pp. 127-142).

Fodor, J. A. (1983). The Modularity of Mind, Cambridge, MA: The MIT Press.

Gebel, H. G. K. (2002). Walls. Loci of Forces. In Gebel, Hermansen and Jensen (Eds.), Magic Practices in the Near Eastern Neolithic: Studies in Early Near Eastern Production, Subsistence and Environment 8 (pp. 119-132).

Gebel, H. G. K. (2013). The Neollithic commodification of stone. In Borrell, Ibanez and Molist (Eds.), Stone Tools in Transition: From Hunter-Gatherers to Farming Societies in the Near East 1 (pp. 191-206).

Gerstl, P. and Pribbenow, S. (1995). Midwinters, end games, and body parts: a classification of part-whole relations. International Journal of HumanComputer Studies, 43 (pp. 865-889).

Habel, C., Pribbenow, S. and Simmons, G. (1995). Partonomies and Depictions: A Hybrid Approach. In Glasgow, Narayanan and Chandrasekaran (Eds.), Diagrammatic Reasoning: Cognitive and Computational Perspectives (pp. 627-653), Cambridge, MA: MIT Press.

Hodder, I. (2006a). The Leopard's Tale: Revealing the Mysteries of Çatalhöyük, London; New York: Thames \& Hudson.

Hodder, I. (2006b). This Old House: At Çatalhöyük, a Neolithic site in Turkey, families packed their mud-brick houses close together and traipsed over roofs to climb into their rooms from above. Natural History Magazine.

Hodder, I. (2012). Entangled: An Archaeology of the Relationships between Humans and Things, Wiley-Blackwell.

Johansson, I. (2006). Formal mereology and ordinary language - Reply to Varzi. Appl Ontol, 1 (pp. 157-161).

Keane, W. (2003). Semiotics and the social analysis of material things. Language and Communication, 23 (pp. 409425).

Keane, W. (2005). In Miller (Ed.), Materiality (pp. 182-205), Durham, NC: Duke University Press.

Machery, E. (2009). Doing without Concepts, Oxford: Oxford University Press.

Mellaart, J. (1967). Çatalhöyük: A Neolithic Town in Anatolia, London: Thames \& Hudson.

Mill, J. S. (1843/1965). On the logic of moral sciences, New York: BobbsMerrill.

Mithen, S. (1996). The Prehistory of the Mind: A Search for the Origins of Art, Religeon and Science, Thames and Hudson. 
Pauketat, T. R. (2013). Bundles of/in/as time. In Robb and Pauketat (Eds.), Big Histories, Human Lives. Tackling problems of scale in archaeology (pp. 3556), Santa Fe (NM): SAR Press.

Ross, W. E. (1924). Aristotle's Metaphysics, Oxford: Clarendon Press.

Szabó, Z. G. (2012). The Case for Compositionality. In Werning, Hinzen and Machery (Eds.), The Oxford Handbook of Compositionality (pp. 64-80), Oxford: Oxford University Press.

Tversky, B. (1989). Developmental Psychology, 25, No. 6 (pp. 983-995).

Tversky, B. (2005). On Exploring Parts and Wholes. In Gero and Maher (Eds.), Computational and Cognitive Models of Creative Design VI (pp. 3-16), Key Centre of Design Computing and Cognition, University of Sydney, Australia.

Winston, M. E. and Herrmann, D. (1987). A taxonomy of part-whole relations. In Chaffin (Ed.), Cognitive Science, 11, No. 4 (pp. 417-444). 